\title{
Characterizing the properties of daily precipitation concentration in Amur River Basin of northeast China
}

\author{
Yousheng Wang 1,2, Jianzhao Guan 1,2 ${ }^{*}$, Xiaoming Zhang ${ }^{1,2}$, Pengfei Du ${ }^{2,3}$, Lei Zhang ${ }^{1,2}$, and Min Luo ${ }^{4}$ \\ ${ }^{1}$ State Key Laboratory of Simulation and Regulation of Water Cycle in River Basin, Beijing, 100048, China \\ ${ }^{2}$ China Institute of Water Resources and Hydropower Research, Beijing, 100048, China \\ ${ }^{3}$ International Research and Training Center on Erosion and Sedimentation, Beijing, 100048, China \\ ${ }^{4}$ College of Soil and Water Conservation, Beijing Forestry University, Beijing, 100083, China
}

\begin{abstract}
The Amur River Basin is one of the most sensitive areas to the effects of climate change. In this study, spatial and temporal analysis of concentration index over the Amur River Basin in northeast China was presented. Precipitation data from 71 meteorological stations for the time series 1980-2018 on daily scale was employed in the study. The results indicated that precipitation events of low-intensity accounted for $28.59 \%$ of rainy days, however, the proportion of rain amount was $1.33 \%$. On the contrary, high- and very high-intensity events accounted for $40.34 \%$ of rainy days and as high as $90.53 \%$ of annual precipitation amount. Precipitation concentration explain the cause of why some regions are prone to be influenced by high intensity precipitation events, spatial distribution of different intensities can be partly interpreted by daily rainfall heterogeneity and regional geomorphology. Furthermore, a significant change toward a stronger precipitation concentration was demonstrated over some regions, and this need concern from the administration.
\end{abstract}

\section{Introduction}

The Amur River Basin is one of the biggest major grain producing area and commercial grain base in China. The basin is a typical climate vulnerable zone and one of the most sensitive areas to the effects of climate change. Some research have been carried out in Amur River Basin on precipitation change, however, few research pay attention to the statistical structure of daily precipitation in recent years.

A very large proportion of precipitation only occur in just a few days, which may give high rise to flash floods or erosion events. This study analyzed the spatial and temporal distribution of concentration index in the Amur River Basin of northeast China. Precipitation data from 71 meteorological stations for the time series 19802018 on daily scale was employed in the study. The results could help better understanding the impact of climate change on precipitation and provide scientific support to soil and water conservation and flood prevention.

\section{Methods}

The statistical structure of daily precipitation, can be adjusted by negative exponential distributions. In this study, daily precipitation was accumulated and analyzed. A concentration curve is plotted with the cumulative percentage of rain amount (y) against the cumulative percentage of rainy days (x) after classifying and tabulating. In the concentration curve, the absolute frequencies decrease in the exponential function. That is, for a specific meteorological station, there are many small daily amounts of precipitation and few large daily amounts (Martin-Vide, 2004). The concentration curve of each station was fitted with exponential function (Eq. 1). The CI could be defined as area between the bisector of the quadrant line and concentration curve (Eq. 2). A definitive integral of the curve exponential between 0 and 100 is applied to calculate the area encircled by the curve; this area is the difference between 5000 and the value calculated from Eq. (3).

$$
\begin{gathered}
y=a e^{b x} \\
C I=2 S^{\prime} / 10000 \\
A^{\prime}=\left[\frac{a}{b} e^{b x}\left(x-\frac{1}{b}\right)\right]_{0}^{100}
\end{gathered}
$$

In order to solve the different threshold and categories of precipitation intensity. Four categories were presented based on percentiles for low- (below the 30th percentile), moderate- (between the 30th and 60th percentiles), high- (between the 60th and 80th percentiles) and very high-intensity (above the 80th percentile) events. Furthermore, precipitation events with amount higher than the 90th percentile for rainy days are classified as extreme events.

\footnotetext{
* Corresponding author: wangyousheng119@163.com
} 
Precipitation data from 71 meteorological stations for the time series 1980-2018 on daily scale was employed to analyse the changing spatial and temporal pattern of precipitation concentration. The CI for each meteorological station was calculated for each year, using the rank-based nonparametric Mann-Kendall method, to detect possible trends. The method could not be affected by the statistical distribution of data and is less sensitive to outliers in the data series.

The Mann-Kendall test statistic (S) is calculated from the following Eqs. (4) and (5):

$$
\begin{aligned}
& \operatorname{sgn}\left(x_{j}-x_{i}\right)=\left\{\begin{array}{cl}
1 ; & \text { If } x_{j}>x_{i} \\
-1 ; & \text { If } x_{j}<x_{i} \\
0 ; & \text { If } x_{j}=x_{i}
\end{array}\right. \\
& S=\sum_{i=1}^{n-1} \sum_{j=i+1}^{n} \operatorname{sgn}\left(x_{j}-x_{i}\right) \\
& \operatorname{Var}(S)=\frac{m(m-1)(2 m+5)-\sum_{i=1}^{P} t_{i}\left(t_{i}-1\right)\left(2 t_{i}+5\right)}{18} \\
& Z_{s}= \begin{cases}\frac{S-1}{\sqrt{\operatorname{Var}(S)},} & \text { If } S>0 \\
0, & \text { If } S>0 \\
\frac{S+1}{\sqrt{\operatorname{Var}(S)},}, & \text { If } S<0\end{cases}
\end{aligned}
$$

\section{Conclusions}

\subsection{General results of daily rainfall indices}

Average precipitation amount per rainy day (RD) for all 71 meteorological stations in Amur River Basin is 5.04 $\mathrm{mm}$, and the coefficient of variation $(\mathrm{CV})$ is $14.86 \%$. Compared with the CV of annual precipitation (21.39\%), the $\mathrm{CV}$ of $\mathrm{RD}$ is much lower. The averaged $\mathrm{CI}$ calculated for the region is 0.72 , and the $\mathrm{CV}$ is $2.08 \%$, with a low standard deviation (0.01). These statistical data show a similar phenomenon on daily and annual scale. Neverthless, different results exhibit when low-, moderate-, high-, very high- and extreme- intensity events are analyzed.

The mean contribution of precipitation amount for extreme events is $52.01 \%$ for the region, and ranges from 48.65 to $57.09 \%$ (with a $\mathrm{CV}$ of $3.45 \%$ ). This contribution accounts for approximately $10.04 \%$ of rainy days (Table 1).

The contribution of low-intensity events accounts for $28.59 \%$ of the rainy day for the entire Amur River basin, representing just $1.33 \%$ of total precipitation amount, with a low CV (5.27\%)(Table 1). These events generally could not induce large disaster or negative influence, due to the small magnitude of precipitation amount and the occurring time of the non-flooding season.

Mean contribution of moderate intensity events accounts for $31.07 \%$ of the rainy days for Amur River Basin, while only contributing $8.14 \%$ of precipitation amount. Low and moderate intensity events show the largest contribution of rainy days $(59.66 \%)$ and a low contribution of precipitation amount (9.47\%). Meanwhile, the mean contribution of high-intensity events is $20.21 \%$ of rainy days and $18.21 \%$ of the precipitation amount, and value of very high-intensity events is $20.13 \%$ of the rainy days and $72.32 \%$ of the precipitation amount. Generally, the high and very high intensity events contribute $40.34 \%$ of the rainy days and as high as $90.53 \%$ of precipitation amount. Consequently, due to the high contribution of precipitation amount and relatively less rainy days, more concern should be paid to the two categories, which may trigger negative influence to the environment.

Table 1 General statistics of daily precipitaiton indices

\begin{tabular}{|c|c|c|c|c|c|c|}
\hline \multicolumn{2}{|c|}{ Parameter } & Min & Max & Mean & Std. & CV \\
\hline \multirow{2}{*}{ P } & $\begin{array}{c}228.8 \\
8\end{array}$ & 818.84 & 515.10 & 110.17 & 21.39 \\
\hline \multicolumn{2}{|c|}{ RD } & 3.02 & 6.14 & 5.04 & 0.75 & 14.86 \\
\hline \multirow{4}{*}{$\begin{array}{c}\text { Contribution } \\
\text { of rainy days } \\
(\%)\end{array}$} & Low & 0.69 & 0.76 & 0.72 & 0.01 & 2.08 \\
\cline { 2 - 7 } & Moderate & 25.30 & 33.57 & 28.59 & 1.51 & 5.27 \\
\cline { 2 - 7 } & Hery high & 19.47 & 21.08 & 20.21 & 0.31 & 1.56 \\
\cline { 2 - 7 } & Extreme & 9.82 & 10.21 & 10.04 & 0.07 & 0.66 \\
\hline \multirow{4}{*}{$\begin{array}{c}\text { Contribution } \\
\text { of } \\
\text { precipitation } \\
\text { amounts (\%) }\end{array}$} & Mow & 0.95 & 2.01 & 1.33 & 0.20 & 15.34 \\
\cline { 2 - 7 } & High & 15.34 & 20.26 & 18.21 & 1.00 & 5.49 \\
\cline { 2 - 7 } & Very high & 68.70 & 77.02 & 72.32 & 1.65 & 2.28 \\
\cline { 2 - 7 } & Extreme & 48.65 & 57.09 & 52.01 & 1.79 & 3.45 \\
\hline
\end{tabular}

Mean annual precipitation (P), Average precipitation amount per rainy day (RD), concentration index (CI), percentages of contribution (\%) for rainy days and precipitation amount, for low, moderate, high, very high and extreme intensity events.

\subsection{Spatial distribution of precipitation intensity and $\mathrm{Cl}$}

Fig.1a shows the heterogeneous exhibition of precipitation intensity, where the most intense rainfall (5.56-5.98 $\mathrm{mm} /$ day) is in the central-southern region (Songnen Plain), and this can be associated with the high-intensity moisture from the Ocean and the topographic countercheck influence from the west (Great Khingan), north (Lesser Khingan Mountains) and east (Changbai Mountains) mountains. The Songnen Plain is ringed by mountains on three sides, and impact of topography and landforms over the moisture from Pacific Ocean in the south is of importance to the distribution of precipitation. 
Fig. 1b shows the spatial distribution of the CI. The highest CI values $(0.736-0.747)$ are mainly found in the west of Amur River Basin (Hulun Buir Plateau). While in the east (Changbai Mountains), the CI values are below the highest values $(0.700-0.710$. The high $\mathrm{CI}$ areas in the Amur River Basin exhibite that the precipitation is irregular, especially in the different intensities of rainfall. Since the CI values mainly reflect the very-high and extreme rainfall, the western Amur River Basin, where the Hulunbuir Plateau located, is more affected by veryhigh and extreme rainfall events.
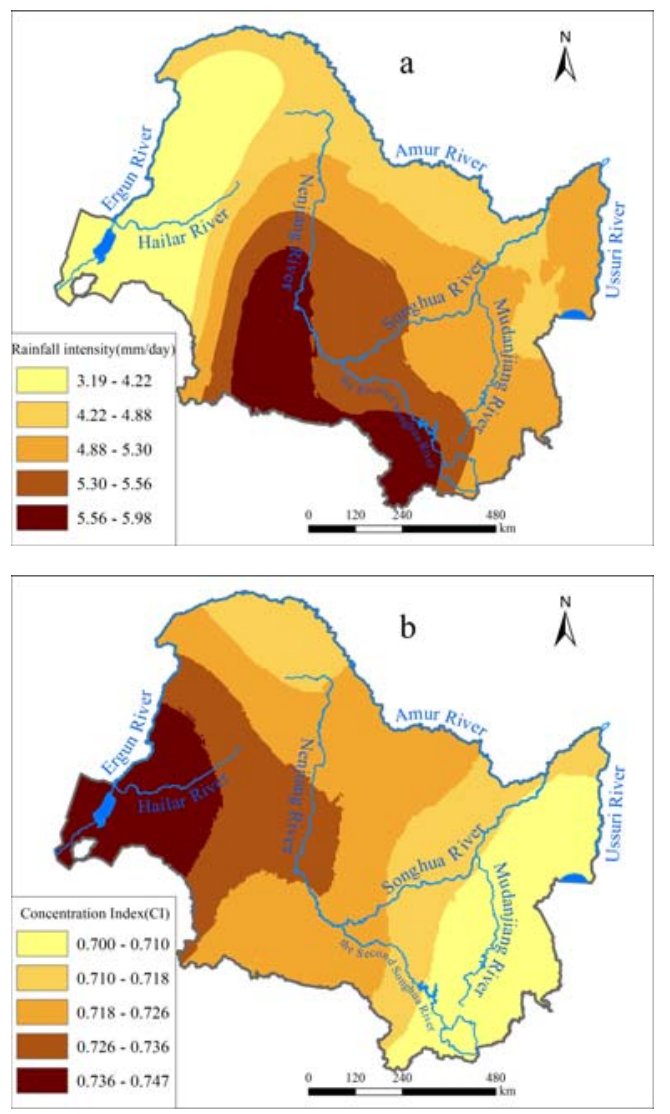

Fig.1. Spatial distribution of (a) average rain amount per rainy day $(\mathrm{RD}) \mathrm{mm} /$ day, (b) the CI concentration index

\subsection{Trends in daily precipitation concentration}

To detect possible trends, the CI was tested for the period of 1980-2018 at each station (Fig 2). The majority of the CI precipitation series do not show significant trend statistically. Nevertheless, in the central south region and northwestern, showed positive trend, and 5 stations significant at $90 \%$ or $95 \%$ level. Especially in the central south region region, where the Songnen Plain located, 3 stations showed significant trend at $90 \%$ or 95\% level. 9 stations showed negative trend, which are scatted in southeastern, northeastern, and southwestern regions.

For the flooding season, the spatial pattern of CI variation trend is similar with that of annual scale in some regions, such as the central south Songnen Plain. However, the number of stations significant at $90 \%$ or $95 \%$ level with negative trend (9 stations) is much greater than the stations with positive trend (1 stations).
As with non-flooding season, the spatial pattern of CI variation trend is similar with that of annual scale in more regions, and the number of stations with negative trend significantly at $90 \%$ or $95 \%$ level (6 stations) is much higher than the stations with positive trend (3 stations). The positive trends are mainly located in northwestern and central south region of Amur River Basin. Generally, increasing CI contributes to negative influence on environment, such as flash floods and soil erosion events, which may complicate good management of water and soil conservation, and more concern should be paid to the region.
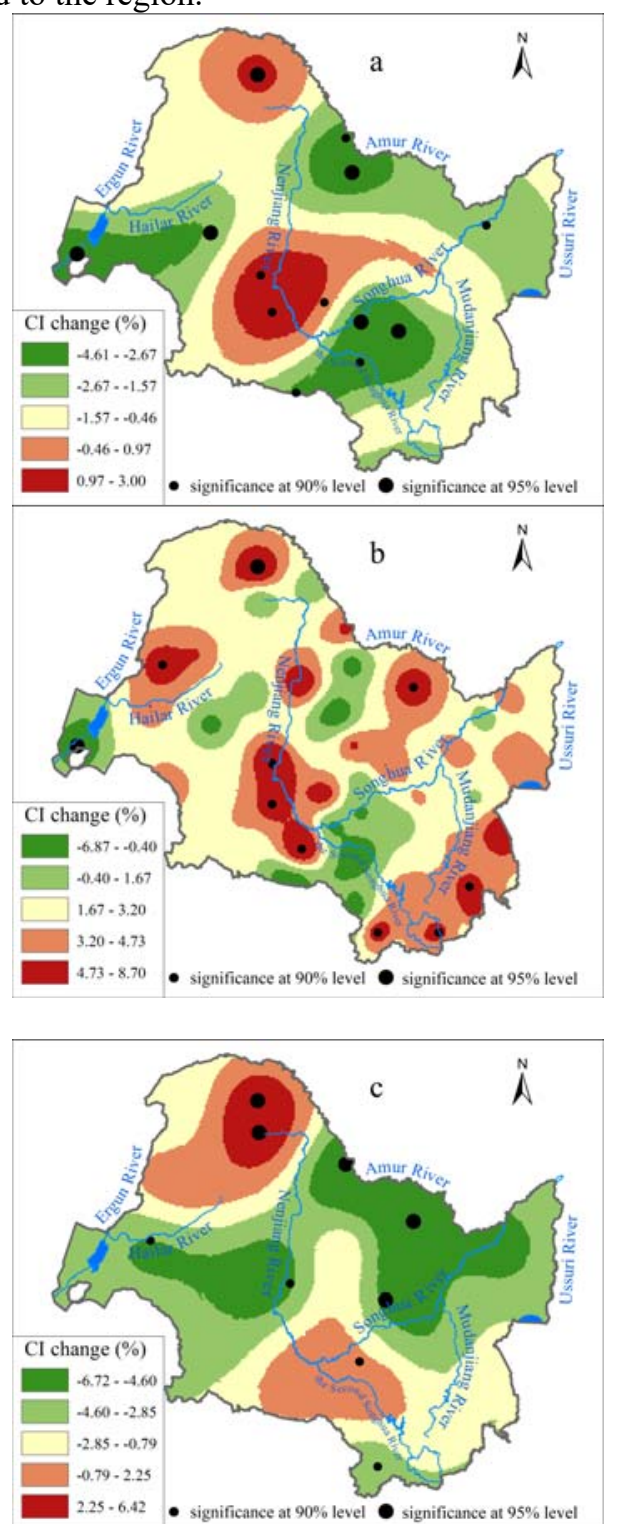

Fig. 2. Spatial distributions of CI variations trend (1980-2018) at $90 \%$ and $95 \%$ significance level: (a) annual, (b) flooding season, (c) non-flooding season

\section{Acknowledgments}

This work was supported by National Key R\&D Program of China (2018YFC 0407304), the IWHR Research \& Development Support Programs (SC0145B172019, SE0145B792017 and SE0145B142018). 


\section{References}

1. Caloiero, T. (2014). Analysis of daily rainfall concentration in New Zealand. Natural Hazards, 72, 389404.

2. Cortesi, N., Gonzalezhidalgo, J. C., Brunetti, M., \& Martinvide, J. (2012). Daily precipitation concentration across Europe 1971-2010. Natural Hazards \& Earth System Sciences, 12, 2799-2810.

3. Jiang, P., Wang, D., \& Cao, Y. (2016). Spatiotemporal characteristics of precipitation concentration and their possible links to urban extent in China. Theoretical and Applied Climatology, 123, 757768.

4. Khalili, K., Tahoudi, M. N., Mirabbasi, R., \& Ahmadi, F. (2016). Investigation of spatial and temporal variability of precipitation in Iran over the last half century. Stochastic Environmental Research and Risk Assessment, 30, 1205-1221.

5. Zhao, L. F. (2016). Variation of precipitation concentration from 1960 to 2014 in the Middle and Lower reaches of the Yangtze River Basin, China. Cuadernos De Investigacion Geografica.

6. Zubieta, R., Saavedra, M., Silva, Y., \& Giráldez, L. (2016). Spatial analysis and temporal trends of daily precipitation concentration in the Mantaro River basin: central Andes of Peru. Stochastic Environmental Research and Risk Assessment, 1-14. 